*Especialista em Direitos Humanos e Políticas Públicas pela Universidade do Vale do Rio dos Sinos - UNISINOS. Especialista em Filosofia na Universidade Federal de Pelotas - UFPEL. Cursando licenciatura em Filosofia na Universidade Federal de Pelotas - UFPEL. Bacharel em Direito pelo Centro Universitário Ritter dos Reis - UNIRITTER.

E-mail: starckadvogado@gmail. com

**Professor na Universidade Federal de Pelotas - Ufpel. Pós- doutor na Eberhard Karls UniversitätTübinjen. Doutor e mestre em Filosofia pela Pontifícia Universidade Católica do Rio Grande do Sul (PUCRS). Graduado em Filosofia pela Universidade Federal de Pelotas Ufpel.

E-mail: keberson.bresolin@gmail. com

\section{Indispensabilidade Da Terra Para A Efetivação Do Direito Humano Ao Alimento Dos Povos Indígenas}

\author{
The Indispensability Of LAND For The Realization OF \\ The Human Right To Food Of Indigenous Peoples
}

\section{Gilberto Starck* Keberson Bresolin**}

Como citar: STARCK, Gilberto; BRESOLIN, Keberson. A indispensabilidade da terra para a efetivação do direito humano ao alimento dos povos indígenas. Revista do Direito Público, Londrina, v. 16, n. 3, p. 123-143, dez. 2021. DOI: 10.5433/24157-108104-1.2021v16n3p.123. ISSN: 1980-511X

Resumo: o presente artigo pretende discutir o direito ao alimento dos povos indígenas. $\mathrm{O}$ estudo foi realizado por meio de revisão bibliográfica e jurisprudencial, partindo-se da previsão contida na Declaração Universal dos Direitos Humanos da ONU, no Pacto Internacional dos Direitos Econômicos, Sociais e Culturais (PIDESC) e da edição da emenda constitucional 64/2010, a qual acrescentou o direito à alimentação ao texto constitucional. A pesquisa está dividida em duas partes. Pretende-se analisar, brevemente e primeiramente, a extensão do direito ao alimento. Em seguida, em que medida o direito ao alimento para os povos indígenas, depende do acesso à terra. Para tanto, será vista a situação atual dos povos indígenas no Brasil e porque esse cenário se reflete na efetivação do direito ao alimento.

Palavras-chave: Direito humano ao alimento; Direito à terra; Povos indígenas.

Abstract: The present article intends to discuss the indigenous peoples' right to food. The study was carried out through bibliographic and jurisprudential revision, based on the provision contained in the UN Universal Declaration of Human Rights, the International Covenant on Economic, Social and Cultural Rights (ICESCR) and the edition of constitutional amendment $64 / 2010$, which added the right to food to the constitutional text. The research is divided into two parts. It is intended to analyze, briefly and first, the extension of the right to food. Then, to what extent the right to food for indigenous peoples depends on access to land. Therefore, the current situation of indigenous peoples in Brazil will be seen and why this scenario is reflected in the realization of the right to food.

Keywords: Human right to food; Right to land; Indian people. 


\section{INTRODUÇÃO}

A preocupação com o tema da insegurança alimentar teve início após o término das duas grandes Guerras Mundiais, momento em que milhões de pessoas morreram por fome no mundo AÇÃO BRASILEIRA PELA NUTRIÇÃO E DIREITOS HUMANOS, 2013). A Declaração Universal dos Direitos Humanos foi o primeiro documento internacional a mencionar o direito ao alimento como sendo digno de proteção e atenção por parte da sociedade mundial (ORGANIZAÇÃO DAS NAÇÕES UNIDAS, 1948).

Em seguida, o Pacto Internacional dos Direitos Econômicos, Sociais e Culturais (BRASIL, 1992), no art. $11^{\circ}$, estabeleceu como função dos Estados que ratificaram o Pacto a adoção de medidas para pôr fim à fome, por meio de ações sustentáveis e concretas (BRASIL, 1992). O Comentário Geral n. 12 do DESC de 1999 é um marco importante no processo de exigibilidade do direito humano ao alimento. Pelo documento, os Estados devem garantir o acesso à alimentação adequada de forma progressiva em âmbito interno (FIAN BRASIL, 2016).

Desde a edição da emenda constitucional 64/2010, o direito ao alimento passou a figurar no rol de direitos constitucionalmente protegidos. Importante lembrar que, a Constituição Federal de 1988 estabelece que, além do rol de direitos fundamentais do art. $5^{\circ}$, também, são direitos tutelados, os previstos em Pactos e Convenções de direitos humanos, os decorrentes do regime e dos princípios (BRASIL, 1988).

O direito ao alimento é considerado um direito humano básico porque a partir dele outros direitos como saúde, cultura e educação poderão ser alcançados. Trata-se de uma "forte aproximação com outros direitos fundamentais, como o direito à vida e à saúde ao lançar a premissa de que o direito à alimentação se converte (ou traduz) em vida e saúde" (CARVALHO, 2012, p. 184). Por isso, "é de importância crucial para a fruição de todos os direitos" (BRASIL. Pacto Internacional dos Direitos Econômicos, Sociais e Culturais, 1992) e está diretamente relacionado com a dignidade humana e à justiça social (ORGANIZAÇÃO DAS NAÇÕES UNIDAS, 1999).

Como parte do considerado mínimo para que haja existência (LEIVAS, 2006, p. 89) o direito à alimentação adquiriu destaque principalmente após o processo de internacionalização dos direitos humanos. A DUDH inovou ao estabelecer os chamados direitos difusos ou transindividuais, fruto de um "forte processo de ampliação e generalização da defesa e da promoção dos direitos humanos" (BRASIL, 2013b).

O presente trabalho analisará a essencialidade da terra para a efetivação do direito ao alimento dos povos indígenas. Primeiramente, se analisará a extensão do direito ao alimento. Em seguida, verificar-se-à a indispensabilidade da terra quando busca-se garantir esse direito em relação aos povos indígenas, num processo que perpassa o enfrentamento da demora e não demarcação das terras indígenas. 


\section{CONSIDERAÇÕES ACERCA DO DIREITO HUMANO AO ALIMENTO}

Como dito, a preocupação com a chamada insegurança alimentar iniciou após a Segunda Guerra Mundial (SILVA, 2014). Josué de Castro (1984, p. 21) afirma que, após esse período de grave desrespeito aos direitos humanos, que resultou na morte de cerca de doze milhões de pessoas por fome, a civilização ocidental começa a tratar o problema dentro de sua extensão.

Abandona-se a preocupação puramente no sentido de que:

A produção, a distribuição e o consumo dos produtos alimentares continuassem a se processar indefinidamente como fenômenos exclusivamente econômicos dirigidos e estimulados dentro dos seus interesses econômicos - e não como fatos intimamente ligados aos interesses da saúde pública.

Aqui, já se percebe que o enfrentamento da fome e a consequente garantia do direito humano ao alimento dependem de mudanças estruturais, para além da distribuição de renda para compra de alimentos. A situação dos povos indígenas, por exemplo, exige a tomada de decisões e escolha de políticas públicas que mexam com problemas históricos como a falta de demarcação das terras tradicionais e a efetivação de outros direitos dos povos indígenas.

Num primeiro momento, a fome foi tratada apenas como a falta de alimento, principalmente nos países pobres. Devido a isso, foram adotadas medidas visando o aumento na produção de alimentos como única solução para enfrentar o problema. No entanto, a produção de alimentos cresceu e a fome não diminuiu (BRASIL, 2017).

Constatou-se que a produção de alimentos era suficiente e que o problema da insegurança alimentar possui relação com fatores como má distribuição de renda e de terra, com a pobreza e com a dificuldade de acesso físico dos alimentos, ou seja, o poder de compra (BRASIL, 2013b). Note-se que a necessidade da terra figura entre os fatores que impedem que a fome diminua e, se trate do problema na sua extensão.

Segundo Hoffmann (1995, p. 159), o acesso ao alimento está diretamente ligado com a distribuição de renda, só com a disposição de valores as pessoas poderão comprar alimentos.

Trata-se de um processo histórico, que nem sempre foi assim: nas primeiras sociedades a busca pelo alimento era algo natural, com a caça, a pesca, a coleta de frutos e a plantação. Só a partir do desenvolvimento das sociedades e do modelo capitalista é que a renda passou a ser importante e a busca pelo alimento tornou-se um processo mercantil. $\mathrm{O}$ acesso ao alimento passou a depender de preço e do quanto de renda o cidadão dispõe (GAMBA; MONTAL, 2009, p. 58).

Por essa razão, os principais projetos desenvolvidos pelo Governo Federal no combate à fome, principalmente após 2002, focaram na garantia da produção de alimentos através do fortalecimento agricultura familiar (do já existente PRONAF) e na distribuição de renda entre a população de baixa renda (Bolsa Família) (MALUF, 2006). Esses programas têm o objetivo de garantir que a quantidade de alimentos produzida seja suficiente para o abastecimento e distribuição de renda entre os grupos sociais mais pobres. 
Hoffmann (1995) aponta que, a quantidade de alimentos produzida no País é suficiente para garantir o abastecimento da população. O problema encontra-se no acesso ao alimento. Logo, são necessárias medidas para garantir renda entre as parcelas mais pobres da sociedade e, ao mesmo tempo, desenvolvimento econômico dos grupos sociais mais vulneráveis. $\mathrm{O}$ autor menciona que somente a melhoria na qualidade de vida desses grupos tornarão o emprego e o alimento possíveis, num círculo que proporciona a melhoria de vida e a diminuição da fome (HOFFMANN, 1995, p. 170).

O Relatório Anual da Comissão Especial de Monitoramento de Violação do Direito Humano à Alimentação Adequada considera que a alimentação é uma necessidade vital para o ser humano e reflete um processo biológico cultural de valores e costumes. Explica que o direito humano ao alimento possui duas dimensões: estar livre da fome e da desnutrição e ter acesso à alimentação adequada. Na primeira, a preocupação é estar livre da fome e das doenças, enquanto a segunda relaciona-se com a ingestão de alimentos saudáveis (BRASIL, 2015).

Conforme Valente (2002), o direito à alimentação adequada visa garantir a todas as pessoas o acesso "aos recursos e aos meios para produzir ou adquirir alimentos seguros e saudáveis que possibilitem uma alimentação de acordo com os hábitos e práticas alimentares de sua cultura, de sua região e de sua origem étnica".

Desse modo, a terra é essencial na efetivação do direito ao alimento dos povos indígenas porque só em seus territórios os indígenas podem desenvolver seus modos de ser e estar no mundo. Só em suas terras podem desenvolver a caça, o plantio e acessar a água, conforme seus costumes, como refere a Convenção 169 da OIT (BRASIL, 2004).

Em 2002, o Relator Especial da ONU definiu o direito ao alimento como sendo "um direito humano inerente a todas as pessoas de ter acesso regular, permanente e irrestrito, quer diretamente ou por meio de aquisições financeiras, a alimentos seguros e saudáveis, em quantidade e qualidade adequadas e suficientes (MALUF, 2006).

Da mesma forma, o Comentário n. 12 do DESC, estabelece que o direito à alimentação depende da disponibilidade de alimento, em quantidade e qualidade adequadas e, também, da acessibilidade física e econômica. Os alimentos precisam ser acessíveis de maneira que o custo com a alimentação não comprometa a fruição de outros direitos (FIAN BRASIL, 2016).

Se considera que o direito ao alimento está garantido quando se tem um cenário de segurança alimentar em que todas as pessoas possuem acesso ao alimento para desenvolver-se com qualidade de vida (BRASIL, 2013b).

A FAO, Organização das Nações Unidas para a Agricultura e Alimentação, considera que segurança alimentar é "a garantia, a todos, de condições de acesso a alimentos básicos de qualidade, em quantidade suficiente, de modo permanente e sem comprometer o acesso a outras necessidades essenciais" (ORGANIZAÇÃO DAS NAÇÕES UNIDAS, 1996). Sendo que o alimento é o meio pelo qual o ser humano poderá manter-se saudável, longe da desnutrição e livre de doenças como desnutrição crônica e retardo no crescimento (HOFFMANN, 1995, p. 159).

Conti (2009, p. 16) afirma que tratar do direito humano ao alimento exige falar-se em 
pobreza, fome, desnutrição e insegurança alimentar. A primeira relaciona-se com a falta de condições econômicas para adquirir os meios básicos para a sobrevivência. A segunda ocorre quando o ser humano não faz a ingestão de alimentos em quantidade e qualidade suficientes para que seu organismo consiga realizar as atividades físicas normalmente. A desnutrição é ocasionada pela não ingestão de alimentos em quantidade adequada. Por fim, a insegurança alimentar está relacionada com a preocupação em conseguir alimentos suficientes.

Ainda, de acordo com o autor, considera-se que uma pessoa se alimenta adequadamente a partir do momento "que ela possui o acesso diário a alimentos em quantidade e qualidade suficiente para atender às necessidades nutricionais básicas de sua vida e saúde" (CONTI, 2009, p. 16). E concluí dizendo que:

O alimento gradualmente adquire sua dimensão humana à medida que é transformado em gente saudável e cidadã, gente bem alimentada e nutrida, gente que se torna sujeito de direitos (...). Ele, ao possuir as condições econômicas de acesso aos alimentos, e as condições socioculturais de ingeri-los adequadamente, cria e recria continuamente as condições de sua sociabilidade e de sua existência (CONTI, 2009, p. 16).

Assim, o direito ao alimento exige tanto quantidade suficiente, como também, valor nutritivo adequado para que o cidadão viva com saúde. Só então, poderá desenvolver suas atividades e usufruir dos demais direitos, visto que a alimentação é necessidade primária, sem a qual outros direitos não poderão ser alcançados.

\section{A TERRA E O DIREITO HUMANO AO ALIMENTO DOS POVOS INDÍGENAS}

No Brasil pouca terra é demarcada, em razão disso, milhares de índios vivem em constantes conflitos fundiários com não índios, obrigados a viver em condições de vulnerabilidade, diante da falta de demarcação das terras tradicionais. Mesmo os índios que estão nas suas terras não possuem segurança jurídica para usufruir dos territórios que lhes pertencem (CONSELHO INDIGENISTA MISSIONÁRIO, 2017).

Para agravar a situação, durante o julgamento do Caso Raposa Serra do Sol, em 2009, o Supremo Tribunal Federal fixou dezenove condicionantes para que seja considerada terra indígena para fins de demarcação. Na ementa do Voto figurou a tese do marco temporal, segundo a qual, é necessário provar que os índios ocupavam a terra que desejam demarcar na data da Promulgação da Constituição Federal de 1988, a saber, 05 de outubro de 1988, ou, que se prove o esbulho renitente (BRASIL, 2009).

Em 2012, na decisão dos embargos declaratórios foi determinado que as condições não são obrigatórias aos casos futuros, devendo o Juiz analisar cada caso. Porém, a tese do marco temporal vem sendo utilizado, tanto pelo Supremo Tribunal Federal como nos Tribunais inferiores com vistas a anular demarcação de terra indígenas já finda ou como argumento para não reconhecimento 
(BRASIL, 2013d).

Assim, se criou mais um entrave para a efetivação do direito à terra que, consequentemente, afeta o direito ao alimento. A tese agrava a situação porque muitos índios são obrigados a deixar suas terras e a viver em beiras de estradas, em situação de extrema vulnerabilidade social, sem acesso a direitos primários, como o alimento. A Constituição Federal não traz nenhuma obrigatoriedade quanto à prova de marco de ocupação para fins de demarcação. Pela Constituição, em se provando as condições de fato deve o Estado demarcar a terra indígena (SILVA, 2016).

O posicionamento adotado pelo Supremo também não leva em consideração a jurisprudência da Corte Interamericana de Direitos Humanos.

A Corte estabeleceu que a terra é essencial para a sobrevivência física e cultural dos povos indígenas. Os Estados que ratificaram a Convenção Americana de Direitos Humanos precisam adotar medidas internas para efetivar o direito à terra dos povos indígenas. Como visto, o marco temporal visa justamente o oposto. No Caso Paraguai x Comunidade indígena Sawhoyamaxa, membros da Comunidade indígena mencionam a falta de alimentos diante da expulsão e impedimento de retorno às terras que anteriormente habitavam (CORTE INTERAMERICANA DE DIREITOS HUMANOS, 2006).

No julgamento do Caso Yakye vs. Paraguai, a Corte determinou que a demora na adoção de medidas internas que visam o reconhecimento e a demarcação das terras indígenas ocasionam violação ao direito à vida, longe de seus territórios as Comunidades indígenas estão privadas do acesso a recursos mínimos para sobreviver, como o alimento, e expostas à pobreza e à doença. Com base na Convenção Americana de Direitos Humanos, o direito de continuar índio depende das ações do Estado. A Corte Interamericana de Direitos Humanos entende que a terra é essencial para a sobrevivência física e cultural dos povos indígenas (BRASIL. Ministério da Justiça, 2014).

A fome é um problema antigo em nosso País. Em 1996, durante a Cúpula Mundial da Alimentação foram lançados a Declaração de Roma sobre a Segurança Alimentar Mundial e o Plano de Ação da Cúpula Mundial da Alimentação (ALENCAR, 2001). Entre os compromissos assumidos pelos países, entre os quais o Brasil, estão, a erradicação da fome, a adoção de um processo justo de distribuição de renda e a implementação de medidas para garantir o acesso físico de alimentos em quantidade e qualidade suficientes para garantir a qualidade de vida dos cidadãos (BRASIL, 2013b).

Em 2002, os países reafirmaram os objetivos da Cúpula de 1996 e o Brasil estipulou uma série de ações que de forma progressiva deviam ser adotadas para garantir o direito ao alimento e a segurança alimentar (ALENCAR, 2001). A implementação do Programa Fome Zero, em 2003, foi umas das primeiras medidas adotada pelo Governo com colaboração da FAO para pôr fim à fome em nosso País (TUBINO, 2003, p. 260).

Apesar dos esforços governamentais, o Brasil ainda possui problemas com a falta de alimentos porque se está consumindo menos alimentos do que determinam as regras de saúde alimentar (BRASIL, 2009). O problema não pode ser visto somente pela prática de políticas públicas afirmativas que enfrentem o problema de forma rasa e momentaneamente. 
Há uma relação com outros setores, como economia e reforma agrária, que precisam funcionar juntos para que o problema seja enfrentado. Nesse sentido, a garantia da terra é essencial no enfrentamento do problema da fome. A partir da terra, comunidades quilombolas, indígenas, integrantes do Movimento Sem-Terra poderão cultivar os alimentos que necessitam.

O Brasil avançou no combate à insegurança alimentar, os casos de desnutrição crônica, fome e extrema pobreza reduziram nos últimos anos (BRASIL, 2014). A implementação de programas sociais como o Bolsa Família e criação do Sistema Nacional de Segurança alimentar e Nutricional colaboraram para reduzir os índices da pobreza extrema e, consequentemente, a fome (BRASIL, 2015).

Porém, dados do IBGE, através do Relatório Síntese de indicadores sociais de 2017, revelam que ocorreu aumento da miséria e da fome no País, motivado principalmente pela desaceleração dos postos de trabalho, queda no consumo das famílias, precarização das condições de emprego, etc. (INSTITUTO BRASILEIRO DE GEOGRAFIA E ESTATÍSTICA, 2017).

José Graziano da Silva (2003, p. 55) explica que as medidas emergenciais adotadas pelo Governo Federal nos últimos anos não solucionaram o problema. São necessárias medidas que estimulem o desenvolvimento local e sustentável aliado ao equilíbrio de renda e de oportunidades. É preciso "reforçar a responsabilidade do Estado na implementação dos direitos econômicos, sociais e culturais e do direito à inclusão social, bem como na pobreza como violação de direitos humanos" (PIOVESAN, 2003, p. 144).

No Brasil, a fome está diretamente relacionada com a má distribuição dos alimentos e com a desigualdade de obtenção de renda do que com a produção (INSTITUTO BRASILEIRO DE GEOGRAFIA E ESTATÍSTICA, 2013). Dados do IBGE apontam que a fome é maior entre a população negra, parda, entre os nordestinos e entre a população com menos escolaridade (INSTITUTO BRASILEIRO DE GEOGRAFIA E ESTATÍSTICA, 2017). Trata-se de uma "situação histórica de insegurança alimentar: milhões de brasileiros não tem acesso a uma alimentação adequada, regular e digna" (SILVA, 2003, p. 55).

Segundo dados da Secretaria de Direitos Humanos do Governo Federal, a agricultura familiar é responsável pela maior parte da produção de alimento em nosso País. Por essa razão, nos últimos anos, uma grande parcela de recurso foi destinada para programas de fortalecimento e fomento da produção familiar como o PRONAF, PAA, PROGER, entre outros (BRASIL, 2013b). Note-se que são programas de incentivo que se relacionam com o direito à terra, considerando que incentivam os pequenos produtores a permanecer no campo.

Apesar desses programas sociais e das estratégias para a implementação da segurança alimentar e nutricional no Brasil, a incidência de insegurança alimentar ainda está presente nos grupos considerados vulneráveis. Os povos indígenas, quilombolas, pessoas de baixa renda e na linha da pobreza são os grupos mais atingidos pela fome em nosso país (INSTITUTO DE PESQUISA ECONÔMICA APLICADA, 2008). 


\subsection{A NECESSIDADE DE DEMARCAÇÃo DAS TERRAS INDÍGENAS}

Em relação aos povos indígenas e aos quilombolas, a insegurança alimentar relaciona-se diretamente com a defesa do meio ambiente, com a preservação de seus territórios e a falta de água (PEREIRA, 2012). O Ministério de Desenvolvimento Social e Combate à Fome traçou projetos específicos para esses grupos. Os povos e Comunidades Tradicionais participam de "Projetos específicos para a estruturação da produção familiar e comercialização, que auxiliam as famílias a produzirem alimentos de qualidade, com regularidade e em quantidade suficiente para seu autoconsumo e geração de excedentes" (BRASIL, 2021).

Nas comunidades tradicionais, a judicialização do direito ao território interfere diretamente na efetivação do direito ao alimento tendo em vista que o acesso às terras é "imprescindível para a consecução de outros direitos humanos, como à cultura, moradia, alimentação adequada, saúde e educação" (FRIGO; PRIOSTE; ESCRIVÃO FILHO, 2010, p. 214). Dessa maneira, a Secretária de Direitos Humanos reconhece que a demarcação e o reconhecimento das terras são prioridades para que o direito ao alimento seja efetivado entre as populações tradicionais (BRASIL, 2013c).

A terra é essencial ao índio e o Estado possui o dever de, comprovadas as situações de fato, reconhecer as terras indígenas (BRASIL, 2018). Quando se omite ou demora no reconhecimento não há efetivação do direito ao alimento também. A linha histórica de violações de direitos dos povos indígenas no Brasil demonstra que pouco tem sido feito em relação ao reconhecimento das terras indígenas.

Os índios brasileiros sofrem constantes violações de direitos humanos desde o início do processo de colonização pelos europeus. Hoje em dia, a demora e a insegurança jurídica impedem que usufruam do direito que lhes garante a Constituição Federal de 1988. Em vista disso, muitas comunidades vivem hoje em beiras de estradas, em péssimas condições de higiene, sem alimento, saneamento, água, impedidos de realizar seus ritos, suas curas e seus modos tradicionais de vida, porque não estão sobre as suas terras (LIEBGOTT, 2018).

Além do aspecto histórico, como a má distribuição de terras, problemas econômicos, que resultam na alta no preço dos alimentos (ORGANIZAÇÃO DAS NAÇÕES UNIDAS PARA A ALIMENTAÇÃO E A AGRICULTURA, 2015), também, colaboram para o crescimento da insegurança alimentar em nosso País. Nesse sentido, o direito humano ao alimento depende da adoção de medidas que alterem as bases das relações econômicas da sociedade brasileira para acabar com as condições estruturais geradoras das desigualdades e da injustiça social (CARVALHO FILHO, 1995).

Apesar de a terra ser essencial para a sobrevivência física e cultural dos povos indígenas, em $60 \%$ dos territórios não há nenhum tipo de processo de demarcação em andamento (SITUAÇÃO..., 2021). Sendo assim, o Estado Brasileiro não está cumprindo com os compromissos assumidos quando da ratificação do PIDESC, entre eles, o dever de garantia do direito humano ao alimento.

A Carta das Mulheres Indígenas ao Estado Brasileiro, do Conselho Nacional de Segurança Alimentar e Nutricional, menciona as ameaças ao direito ao alimento desses povos, a necessidade 
de estratégias de atuação do Estado para garantir a terra. $\mathrm{O}$ grupo considera que a segurança alimentar perpassa o território, saúde, educação, hábitos alimentares e a qualidade dos alimentos. Reafirmam a importância do meio ambiente e dos seus territórios para a garantia de alimento com qualidade. Retratam as mudanças alimentares que incluiu alimentos não utilizados anteriormente como o açúcar na dieta dos membros da Comunidade (BRASIL, 2004). Ainda, que o plano de ação do Governo oferece cestas básicas com alimentos industrializados, desestimulando a continuação das práticas tradicionais e aumentando o quadro de doenças. Por isso, consideram como essenciais ações com vistas à demarcação de terras indígenas e políticas públicas voltadas para a continuação e fortalecimento da cultura e práticas alimentares tradicionais (BRASIL, 2013a).

Como aponta Souza (2009), trata-se das mesmas preocupações dos Mbyá-Guarani da Região Sul do País. Grande parte desse povo vive em assentamentos em beiras de estradas, sofrem com o desmatamento e com o uso excessivo de agrotóxicos. Os últimos anos foram difíceis em relação aos processos demarcatórios. Principalmente pela forte cultura colonial presente no Rio Grande do Sul e dos processos históricos de disputa pela terra e das regiões pluviais. Os guaranis se deslocaram muitas vezes, como ritual e em busca de alimentos. As tentativas de implementação de políticas públicas, no entanto, não fogem do já conhecido paternalismo.

Conforme Tempass (2008), dentro das Comunidades indígenas Mbyá-Guarani, a busca pelo alimento tem um protagonismo feminino e se dá em pequenos grupos, com organização própria. O alimento possui uma dimensão comunitária e pertence a todos. Em momento de escassez alimentar, alguns grupos chegam a passar fome. Do mesmo modo, a preparação da terra se dá em conjunto. A terra é essencial e as condições ecológicas influenciam na quantidade de alimento obtida. Os alimentos possuem uma dimensão espiritual e necessitam da terra para existirem, como exemplo o consumo de grãos. A apropriação das terras pelos brancos impede o plantio de alimentos e a caça. Retira-se o direito de cultuar seus costumes alimentares

O fato é que diante das poucas políticas demarcatórias de terras tradicionais indígenas, se alterou a forma como se busca o alimento. A forma tradicional de se cultivar alimentos, que envolve a cultura e o respeito aos rituais para os deuses, se transformou e atualmente, para sobreviver, os índios precisam comprar fiado, trocado ou escondido. Abandona-se a ideia tradicional de se alimentar em conjunto, em abundância, os alimentos não precisam mais vir da terra já que são comprados no mercado e industrializados (TESTA, 2014).

Nota-se aqui, que ao não efetivar o direito à terra, também, não se pode cultivar as formas tradicionais de alimentação, ou seja, perde-se uma cultura pela assimilação dos modos de se obter alimentos dos não índios. Dessa maneira, o direito ao alimento do índio envolve, também, os direitos contidos na Convenção 169 da OIT, de autodeterminação, de culto às culturas, o modo de ser e estar neste mundo.

\subsection{O ENFRENTAMENTO DA FOME NOS ÚLTIMOS ANOS}

De acordo com a Organização das Nações Unidas (ONU), a fome voltou a crescer no 
mundo. Com base no estudo "The State of Food Security and Nutrition in the World 2017" , a Organização, menciona que em 2016, 815 milhões de pessoas sofreram com má alimentação no mundo, principalmente em virtude da desaceleração econômica e da fragilidade ambiental (ORGANIZAÇÃO DAS NAÇÕES UNIDAS, 2017).

Ao mesmo tempo, milhões de brasileiros encontram-se em situação de insegurança alimentar, como é o caso dos povos indígenas. Esses povos possuem uma relação diferenciada com a terra porque nela está a sobrevivência física e cultural desses povos. Para Bragato (2016) a restrição e o confinamento dos índios em reservas os impedem de desenvolver seus modos tradicionais de vida e de produção de alimentos. Essa é a situação dos índios Guarani Kaiowá no Mato Grosso do Sul, os quais lutam pelos seus territórios tradicionais, diante da ineficiência de medidas por parte do Estado brasileiro e o estabelecimento da tese do marco temporal (SANTOS, 2015),

Pela Declaração das Nações Unidas sobre Direitos dos Povos Indígenas, proclamada em 2007:

Os povos indígenas têm direito as terras, territórios e recursos que tradicionalmente tem possuído ocupado ou de outra forma ocupado ou adquirido. 2. Os povos indígenas têm direitos a possuir, utilizar, desenvolver e controlar as terras, territórios e recursos que possuem em razão da propriedade tradicional, ou outra forma de tradicional de ocupação ou utilização, assim como aqueles que tenham adquirido de outra forma. 3. Os Estados assegurarão o reconhecimento e proteção jurídica dessas terras, territórios e recursos. O referido reconhecimento respeitará devidamente os costumes, as tradições e os sistemas de usufruto da terra dos povos indígenas. (ORGANIZAÇÃO DAS NAÇÕES UNIDAS, 2007).

Em se tratando de povos indígenas, o alimento relaciona-se com a proteção do meio ambiente, com as unidades de conservação e o desenvolvimento sustentável. Há, desse modo, exigência de meios que permitam o acesso ao alimento, moradia, com respeito ao modo tradicional de vida desses povos (SANTILLI, 2005).

O Relatório "América Latina e o Caribe - Panorama da segurança alimentar e nutricional" produzido pela FAO, Organização Pan-Americana da Saúde e OMS, menciona que nos últimos anos houve aumento da área agrícola na América Latina e Caribe, também, houve diminuição da área coberta pelas florestas e o aumento dos desastres naturais, o que representa uma ameaça para a efetivação do direito humano ao alimento. Ainda, pelo Documento, fatores como o preço dos alimentos e o contexto econômico condicionam a efetivação do direito humano ao alimento (ORGANIZAÇÃO DAS NAÇÕES UNIDAS PARA A ALIMENTAÇÃO E A AGRICULTURA, 2017)

A terra garante que o índio possa produzir seus alimentos (ORGANIZAÇÃO DAS NAÇÕES UNIDAS, 2007), consiga caçar, tenha acesso à água, consiga realizar seus rituais de cura. É, assim, essencial para que o índio tenha o que comer.

É exatamente isso que aponta o estudo feito pela Fian Brasil. A garantia do alimento no 
Brasil depende do enfrentamento da questão da reforma agrária, da garantia dos territórios aos índios e comunidades quilombolas, o fortalecimento da agricultura familiar, etc. Justamente o oposto do que vem acontecendo atualmente e que é causa da falta ou má alimentação: apoio ao agronegócio; uso de agrotóxicos, má distribuição das terras, falta de incentivos a hábitos alimentares saudáveis, mercantilização da terra (FIAN BRASIL, 2017).

O Relatório enumera ainda que a melhora na efetivação do direito humano ao alimento dos povos indígenas iniciada em 2006 com a política de SAN, se desfez a partir da entrada do novo Governo em 2016. Em razão disso, grupos como os índios estão entre os mais afetados pela insegurança alimentar (FIAN BRASIL, 2017).

A alimentação e a nutrição dos povos indígenas dependem do acesso à terra. A FIAN - Organização pelo Direito Humano à Alimentação e à Nutrição Adequadas, destaca a inconstitucionalidade do marco temporal e o caso dos povos indígenas no Mato Grosso do Sul:

Em 2005, por exemplo, a morte por desnutrição de mais de 20 crianças em apenas duas aldeias (Bororó e Jaguapiru), no Mato Grosso do Sul, chamou a atenção da imprensa nacional e colocou a exigência de medidas do Estado brasileiro para reverter este quadro, especialmente no que se refere à garantia de territórios e acesso a recursos naturais necessários à sobrevivência física e cultural dos Guarani e Kaiowá. Em 2010, sem avançar com a demarcação das terras indígenas pelo governo federal, a Secretaria Especial de Saúde Indígena (SESAI) confirmou o alarmante índice de 32,11 mortes de crianças menores de 1 ano de idade para cada 1000 nascimentos nas aldeias indígenas do município de Dourados (MS), sendo que a média nacional era de 19 mortes para cada 1000 nascimentos (FIAN BRASIL, 2017).

O estudo organizado pela FIAN sobre a situação da alimentação dos povos indígenas Guarani Kaiowá no Mato Grosso aponta a responsabilidade do Estado de respeitar, proteger, promover e prover os direitos dos povos indígenas. Ainda, mostra que o aumento desenfreado do latifundiário e das monoculturas têm aumentado os conflitos por terras entre índios e não índios. Relata a situação grave em que esses povos se encontram, os entraves jurídicos para a garantia da terra e o aumento no número de suicídios. O Documento apresenta uma série de violações aos direitos dos povos indígenas, entre essas, do direito ao alimento que perpassa desde o acesso à terra ao agronegócio e o uso excessivo de agrotóxicos que comprometem a produção e o acesso a alimentos saudáveis (FIAN BRASIL, 2016).

O documento Atlas do Agronegócio de 2018 indica que os reflexos da colonização estão na distribuição da terra em nosso País. Segundo o documento, 51,19\% das terras agrícolas brasileiras estão em poder de $1 \%$ dos proprietários rurais. É um problema que se estende desde a Lei de Terras, de 1850. O estudo revela problemas como a enorme produção de alimentos geneticamente modificados, a concentração da produção e da distribuição de alimentos. Em relação aos povos indígenas, a criação do marco temporal que impede que os índios usufruam com segurança de seus territórios tradicionais (SANTOS; VERENA, 2018).

Em 2016, uma comitiva do CONSEA identificou um quadro de violência, mortes, preconceito e violações de direitos humanos na comunidade Guarani e Kaiowá no Mato Grosso do Sul. Além disso, constatou que esse povo vivia em condições de insegurança alimentar e 
nutricional, motivado principalmente pela falta de políticas públicas estatais adequadas (BRASIL, 2016).

\subsection{A Exigibiliddade do Direito ho Alimento}

No tocante à exigibilidade do direito humano ao alimento, pode-se requer administrativamente, politicamente, quase judicialmente e judicialmente (AÇÃO BRASILEIRA PELA NUTRIÇÃO E DIREITOS HUMANOS, 2013). A respeito desse último, em 2013, o Ministério Público Federal interpôs Ação Civil Pública em face da União, Fundação Nacional de Saúde - FUNASA e da Fundação Nacional do Índio - FUNAI, para assegurar direitos fundamentais básicos como o alimento às famílias de índios da tribo Maxakalis, no Estado de Minas Gerais. Em sede de apelação, o Tribunal Regional Federal da Primeira Região reconheceu a falta de um projeto econômico de autosustentação para o desenvolvimento dessa comunidade tradicional e condenou os apelados a implementar "projeto econômico e social de autosustentação nos territórios habitados pelos índios Maxakalis, bem como, forneçam, mensalmente, cestas básicas de alimentos às respectivas famílias indígenas" (BRASIL, 2013e).

Como visto, diante de uma situação de comprovada violação de direitos humanos de povos indígenas, entre as quais a falta de alimento, o Judiciário atuou, exigindo medidas efetivas do Estado com vistas a mudar esse cenário e proteger os direitos dos índios da tribo Maxakalis.

Ainda sobre a judicialização do direito ao alimento, a Índia mostra-se um exemplo de como a judicialização pode desencadear ações concretas por parte do Estado no combate à fome.

A Suprema Corte Indiana, por meio de pedido formulado via Ação Civil Pública, considerou que o direito ao alimento está relacionado com a dignidade e a manutenção da vida. Por esse motivo, emitiu orientações ao Estado Indiano para que, diante da grave crise de alimentos, fosse criado programas sociais com a finalidade de erradicar a fome no País. Entre as medidas adotadas pelo Estado estão a prestação de alimentos aos grupos em maior risco, previamente mapeados, a realização de parcerias entre o terceiro setor e ações conjuntas entre os Ministérios da Agricultura. Desenvolvimento Rural e Desenvolvimento de Mulheres de Crianças (PINHEIRO; THOMAS, 2012).

Assim, desde o início dos anos 2001, o Judiciário Indiano vem emitindo importantes decisões desde que a demanda pelo direito ao alimento chegou à Corte Suprema Indiana. Em 2002, foi proferida decisão em que responsabiliza os secretários-chefes dos Estados pelas mortes por fome no País. A fim de acabar com a fome, a Índia cadastrou as pessoas em situação de risco e, posteriormente, forneceu uma espécie de cartão refeição para os grupos em situação de insegurança alimentar para que pudessem comprar alimentos com desconto. Além disso, foram criados grupos de comissionários para acompanhar o andamento das medidas nos estados indianos (ÍNDIA, 2002).

Em nova ordem emitida em 2006 na Ação Civil nº 196 de 2001, a Corte determinou que o Estado indiano deveria instituir um sistema público de distribuição de alimentos, com prioridade 
para aldeias e grupos em maior vulnerabilidade (ÍNDIA, 2006).

$\mathrm{Na}$ Ação Civil levada à Suprema Corte Indiana em 2001, a Corte se manifestou no sentido de que a fome é um grave problema social, apesar de haver abundância de alimentos. O que se assemelha com o caso brasileiro: há alimentos suficientes, mas não há distribuição equânime entre a população.

Da mesma forma, determinou que os grupos mais vulneráveis fossem mapeados e cadastrados para recebimento do cartão refeição (Antyodaya), com concessão de desconto na compra de cereais. Como plano de enfrentamento da fome foi implantado o plano de refeição do meio dia nas escolas indianas, o qual fornece alimentação aos alunos indianos seguindo uma dieta adequada de calorias (ÍNDIA, 2001).

Em se tratando da efetivação do direito ao alimento dos povos indígenas, a terra é essencial porque "a garantia do direito humano à alimentação e à nutrição adequadas desses povos tem como principal pré-requisito o direito a seus territórios ancestrais, pois é através da terra que garantem sua subsistência e seu modo de ser tradicional" (FIAN BRASIL, 2017).

De acordo com as Diretrizes Voluntárias sobre a Governança Responsável, os Estados precisam:

Esforçar-se para assegurar a governança fundiária responsável, porque a terra e os recursos pesqueiros e florestais são fundamentais para a consecução dos direitos humanos, da segurança alimentar, da erradicação da pobreza, dos meios de subsistência sustentáveis, da estabilidade social, da segurança da habitação, do desenvolvimento rural e do crescimento social e econômico (DIRETRIZES..., 2015).

No mesmo sentido, as diretrizes voluntárias para a efetivação do direito ao alimento da FAO, estabelece a necessidade da terra, de reforma agrária que contemple a produção e o acesso de alimentos, reforçar o acesso dos menos favorecidos à terra e a utilização sustentável da terra. Menciona que se deve dar atenção às comunidades indígenas em relação ao uso da terra e dos recursos genéticos para a alimentação e a agricultura (FIAN BRASIL, 2016).

Num momento em que o Judiciário brasileiro insiste em exigir a comprovação de um marco temporal inexistente para reconhecimento e demarcação de terras indígenas e que o Congresso Nacional segue tentando a aprovação da PEC 215, se tem um desafio a enfrentar: garantir que o índio brasileiro sobreviva física e culturalmente, com terra e alimento.

\section{CONCLUSÃO}

No Brasil, pouca terra é demarcada. Onde houve demarcação, vive-se em estado de insegurança, na medida em que os conflitos por terra envolvendo índios e não índios são recorrentes. Trata-se de um problema histórico, iniciado com o processo de colonização pelos países europeus 
e que se agravou no período da ditadura militar quando, em nome do desenvolvimento econômico e da expansão, muitos índios foram expulsos de suas terras.

Considerando que a terra é essencial para a sobrevivência física e cultural dos povos indígenas e que somente quando estão em seus territórios possuem acesso aos alimentos, verificase dependência entre a efetivação do direito à terra e do alimento, haja vista que há índio morrendo por fome no País.

Não garantir terra significa não garantir o direito humano ao alimento.

$\mathrm{O}$ Estado precisa adotar medidas para efetivar o direito à terra dos povos indígenas. Também, deve garantir que o direito ao alimento seja concretizado e acabe com o estado de vulnerabilidade social em que essas comunidades se encontram, tanto as que vivem em conflitos e que estão sobre as suas terras, quanto as que foram expulsas e estão vivendo em beiras de estradas.

É um problema complexo que demanda estudo sobre as situações que levaram a esse cenário. Ao mesmo tempo em que sejam vistas as relações históricas que ocasionaram a vulnerabilidade atual dos povos indígenas, também, se faz necessário tratar problemas atuais. Como exemplo, a tese do marco temporal, a qual, praticamente anula as chances de se demarcar terras indígenas e, consequentemente, efetivar o direito humano ao alimento.

Se há índio longe de suas terras, há índio em estado de insegurança alimentar. Em vista disso, mais do que garantir o alimento, a efetivação do direito à terra envolve direitos culturais dos povos indígenas, os quais são essenciais para a sobrevivência física e cultural desses povos.

O direito ao alimento tem tanto a dimensão de manter a sobrevivência física dos povos indígenas, como também, possui um aspecto de manutenção dos direitos culturais porque reflete processos específicos do modo de ser dos índios. Para tanto, cumpre tratar de problemas históricos como o reconhecimento dos direitos desses povos e a distribuição da terra.

\section{REFERÊNCIAS}

AÇÃO BRASILEIRA PELA NUTRIÇÃO E DIREITOS HUMANOS. O Direito humano à alimentação adequada e o sistema nacional de segurança alimentar e nutricional. Brasília: ABRANH, 2013. Disponível em: http://www.nutricao.ufsc.br/files/2013/11/ ApostilaABRANDHModulo1.pdf. Acesso em: 24 set. 2018.

ALENCAR, Álvaro Gurgel de. Do conceito estratégico de segurança alimentar ao plano de ação da FAO para combater a fome. Revista Brasileira de Política Internacional, Brasília, v. 44, n. 1, p. 137-144, jun. 2001. Disponível em: https://www.scielo.br/j/rbpi/a/ TwYTSm8zRGc8zNcLw4NZJjv/?lang=pt. Acesso em: 23 nov. 2021.

BRAGATO, Fernanda Frizzo. Direitos territoriais indígenas e prevenção de atrocidades no Brasil: o papel do Supremo Tribunal Federal discutido em Amicus Curiae. In: ENGELMANN, Wilson; ROCHA, Leonel Severo; STRECK, Lenio Luiz. Constituição, sistemas sociais e hermenêutica: anuário do programa de Pós-graduação em Direito da UNISINOS: mestrado e doutorado. Porto Alegre: Livraria do Advogado Editora, 2016. p. 53 - 68. 
BRASIL. Ministério da Saúde. Brasil assume compromisso para melhorar nutrição. ACT Promocão da Saúde. São Paulo, 20 nov. 2014. Disponível em: https://actbr.org.br/post/brasilassume-compromisso-para-melhorar-nutricao/15783/. Acesso em: 23 nov. 2021.

BRASIL. Articulação Nacional de Agroecologia. Carta das mulheres indígenas ao estado brasileiro. Brasília; CONSEA, 2013a. Disponível em: https://agroecologia.org.br/wp-content/ uploads/2013/12/carta-das-mulheres-indigenas-1.pdf. Acesso em: 23 nov. 2021.

BRASIL. Conselho Nacional de Segurança Alimentar e Nutricional. Princípios e diretrizes de uma política de segurança alimentar e nutricional. Brasília: CONSEA, 2004. Disponível em: https://www.ipea.gov.br/participacao/images/pdfs/conferencias/Seguranca_Alimentar_II/textos_ referencia_2_conferencia_seguranca_alimentar.pdf. Acesso em: 23 nov. 2021.

BRASIL. [Constituição (1988)]. Constituição da República Federativa do Brasil de 1988. Brasília: Presidência da República, 1988. Disponível em: http://www.planalto.gov.br/ccivil_03/ constituicao/constituicaocompilado.htm. Acesso em: 29 mar. 2018.

BRASIL. Decreto no 5.051, de 19 de abril de 2004. Promulga a Convenção $n^{0} 169$ da Organização Internacional do Trabalho - OIT sobre Povos Indígenas e Tribais. Brasília: Presidência da República, 2004. Disponível em: http://www.planalto.gov.br/ccivil_03/_ato20042006/2004/decreto/d5051.htm. Acesso em: 24 out. 2018.

BRASIL. Ministério da Cidadania. Direito à alimentação. Brasília: Ministério da cidadania, 2021. Disponível em: http://mds.gov.br/assuntos/seguranca-alimentar/direito-a-alimentacao/ povos-e-comunidades-tradicionais. Acesso em: 24 set. 2018.

BRASIL. Ministério da Educação. Alimentação e nutrição no Brasil. Brasília: UNB, 2009. Disponível em: http://portal.mec.gov.br/index.php?option=com docman $\&$ view $=$ download\&alias $=610$-alimentacao-e-nutricao-no-brasil\&Itemid=30192. Acesso em: 24 out. 2018.

BRASIL. Ministério da Justiça. Jurisprudência da Corte Interamericana de Direitos Humanos. Secretaria Nacional de Justiça. Comissão de Anistia. Corte Interamericana de Direitos Humanos. Tradução da Corte Interamericana de Direitos Humanos. Brasília: Ministério da Justiça, 2014.

BRASIL. Ministério da Saúde. Política nacional de alimentação e nutrição. Brasília: ministério da saúde, 2013b. Disponível em: http://bvsms.saude.gov.br/bvs/publicacoes/politica nacional_alimentacao_nutricao.pdf. Acesso em: 24 set. 2018.

BRASIL. Pacto internacional dos direitos econômicos, sociais e culturais. Brasília, 1992. Disponível em: http://www.oas.org/dil/port/1966\%20Pacto\%20Internacional\%20sobre\%20 os $\% 20$ Direitos $\% 20$ Econ $\%$ C3\%B3micos, $\% 20$ Sociais\%20e $\% 20$ Culturais.pdf. Acesso em: 24 set. 2018.

BRASIL. Relatório anual da Comissão Especial de Monitoramento de Violação do Direito 
Humano à Alimentação Adequada. Brasília, 2015. Disponível em: http://pt.slideshare.net/ mdscomunicacao/relatrio-fao-o-estado-da-insegurana-alimentar-no-mundo-2015. Acesso em: 24 set. 2018.

BRASIL. Secretária de Direitos Humanos da Presidência da República. Direito à alimentação adequada. Brasília: SDHP/PR, 2013c. Disponível em: http://unesdoc.unesco.org/ images/0022/002254/225425POR.pdf. Acesso em: 24 set. 2018.

BRASIL. Supremo Tribunal Federal. Embargos de declaração na petição 3.388-4. Embargos de declaração. Ação popular. Embargos de demarcação da terra indígena raposa serra do sol. Relator (a): Min. Luís Roberto Barroso, julgado em 23/10/2013. Brasília: Supremo Tribunal Federal, 2013d. Disponível em: http://www.conectas.org/arquivos/editor/files/Inteiro\%20 Teor\%20do\%20Ac\%C3\%B3rd\%C3\%A3o\%20-\%20PET\%203388\%20-\%20Embargos.pdf. Acesso em 29 mar. 2018.

BRASIL. Supremo Tribunal Federal. Petição 3.338-4. Relatora: Min. Ayres Britto, julgado em 19 de março de 2009. DECISAO: (Ref. às Petições 33070 e 34231) O Ministério Público Federal e a União ingressam nos autos desta ação popular com petições $\left(n^{\circ} \mathrm{s}\right.$ 33070 e 34231, respectivamente) versantes sobre a execução do que foi decidido por este Supremo Tribunal na sessão plenária de 19/03/2009. Relator: Min. Carlos Ayres Britto, julgado em 9/04/2009. Disponível em: http://www.stf.jus.br/portal/geral/verPdfPaginado. asp $\mathrm{id}=603021 \&$ tipo $=\mathrm{AC} \&$ descricao $=$ Inteiro $\% 20$ Teor $\% 20 \mathrm{Pet} \% 20 / \% 203388$. Acesso em $29 \mathrm{mar}$. 2018.

BRASIL. Tribunal Regional Federal da Primeira Região. Processo no ${ }^{0}$ 2007.38.13.0016797. Constitucional. Ação civil pública. Políticas públicas. Implementação de projeto econômico de auto-sustentação nos territórios habitados pelos índios maxakalis. Fornecimento de cestas-básicas de alimentos às respectivas famílias indígenas, até que se implemente o aludido projeto. Possibilidade. Prevalência do direito à vida, à saúde e à dignidade da pessoa humana. Legitimidade da funasa para figurar no pólo passivo da presente relação processual. Relator: Des. Fed. Souza prudente, 2 dez. 2013. Brasília: Tribunal Regional Federal, 2013e. Disponível em: http://processual.trf1.jus.br/ consultaProcessual/processo.php?trf1_captcha_id=13e86714907c5117b925b23cd96a0a7f\&trf1_ captcha $=68$ vr\&enviar $=$ Pesquisar\&proc $=16793320074013813 \&$ secao $=$ TRF. Acesso em: 24 set. 2018.

CARVALHO, Osvaldo Ferreira de. O direito fundamental à alimentação e sua proteção jurídico- internacional. Revista do Direito Público, Londrina, v. 7, n. 2, p. 181-224, maio/ ago. 2012. Disponível em: http://www.uel.br/revistas/uel/index.php/direitopub/article/ viewFile/11174/11280. Acesso em: 24 set. 2018.

CARVALHO FILHO, José Juliano de. A produção de alimentos e o problema da segurança alimentar. Estudos avançados, São Paulo, v. 9, n. 2, ago. 1995. Disponível em: http://www. scielo.br/scielo.php?script $=$ sci_arttext\&pid=S0103-40141995000200008. Acesso em: 25 set. 2018 .

CASTRO, Josué de. Geografia da fome. 10. ed. Rio de Janeiro: Antares, 1984. Disponível em: http://pt.scribd.com/doc/23242230/Josue-de-Castro-Geografia-da-Fome\#scribd. Acesso em: 24 
set. 2018.

CONSELHO INDIGENISTA MISSIONÁRIO. Relatório violência contra os povos indígenas no brasil: dados de 2017. Brasília: CIMI, Disponível em: https://cimi.org.br/wp-content/ uploads/2018/09/Relatorio-violencia-contra-povos-indigenas_2017-Cimi.pdf. Acesso em: 24 out. 2018.

CONTI, Irio Luiz. Segurança alimentar e nutricional: noções básicas. Passo Fundo: IFIBE, 2009.

\section{CORTE INTERAMERICANA DE DIREITOS HUMANOS. Caso Comunidad Indígena}

Sawhoyamaxa vs. Paraguay. 2006. Disponível em: http://www.corteidh.or.cr/docs/casos/ articulos/seriec_146_esp2.pdf. Acesso em: 28 mar. 2018.

DIRETRIZES voluntárias sobre a governança responsável da terra, dos recursos pesqueiros e florestais no contexto da segurança alimentar nacional. Brasília: Ideal, 2015. Disponível em: https://biowit.files.wordpress.com/2010/11/diretrizes-web.pdf. Acesso em: 23 de nov. 2021.

FIAN BRASIL. Da democratização ao golpe: avanços e retrocessos na garantia do direito humano à alimentação e à nutrição adequadas no Brasil. Disponível em: https://fianbrasil.org.br/ wp-content/uploads/2017/06/Publica\%C3\%A7\%C3\%A3o-Completa-Informe-Dhana.pdf. Acesso em: 23 nov. 2021.

FIAN BRASIL. O Direito humano à alimentação adequada e à nutrição do povo Guarani e Kaiowá: um enfoque holístico. Disponível em: https://fianbrasil.org.br/wp-content/ uploads/2016/12/Fian-Portugues-WEB-Single-Pages-Small.pdf. Acesso em: 23 nov. 2021.

FIAN BRASIL. Organização pelo Direito Humano à Alimentação e à Nutrição Adequadas. Comentário Geral número 12. O direito humano à alimentação (art. 11). Disponível em: https://fianbrasil.org.br/wp-content/uploads/2016/09/Coment\%C3\%A1rio-Geral-12.pdf. Acesso em: 23 nov. 2021.

FRIGO, Darci; PRIOSTE, Fernando; ESCRIVÃO FILHO, Antônio Sérgio (org). Justiça e direitos humanos: experiências de assessoria jurídica popular. Curitiba: Terra de Direitos, 2010.

GAMBA, Juliane Caravieri Martins. MONTAL, Zélia Maria Cardoso. O direito humano à alimentação adequada: revisitando o pensamento de Josué de Castro. Revista Jurídica da Previdência, Brasília, v. 11, n. 95, p. 58-82, out.2009/jan.2010. Disponível em: https:// revistajuridica.presidencia.gov.br/index.php/saj/article/download/226/215. Acesso em: 24 set. 2018.

ÍNDIA. Interim Order de 29 de outubro de 2002 sobre o writ petition (civil) no 196 de 2001. Disponível em: http://www.righttofoodindia.org/orders/interimorders.html\#top. Acesso em: 09 out. 2018 .

ÍNDIA. Interim Order de 13 de dezembro de 2006 sobre o writ petition (civil) no 196 de 2001. Disponível em: http://www.righttofoodindia.org/orders/interimorders.html\#top. Acesso 
em: 09 out. 2018.

INSTITUTO BRASILEIRO DE GEOGRAFIA E ESTATÍSTICA. Pesquisa suplementar de segurança alimentar PNAD 2013: a percepção das famílias em relação ao acesso aos alimentos. Rio de Janeiro: IBGE, 2014. Disponível em: http://www.ibge.gov.br/home/presidencia/noticias/ imprensa/ppts/00000020112412112014243818986695.pdf. Acesso em 24 set. 2018.

\section{INSTITUTO BRASILEIRO DE GEOGRAFIA E ESTATÍSTICA. Síntese de indicadores} sociais: uma análise das condições de vida da população brasileira. Rio de Janeiro: IBGE, 2017. Disponível em: https://biblioteca.ibge.gov.br/visualizacao/livros/liv101459.pdf. Acesso em: 25 set. 2018.

INSTITUTO DE PESQUISA ECONÔMICA APLICADA. Políticas sociais: acompanhamento e análise. Brasília: IPEA, 2018. Disponível em: http://portal.mec.gov.br/arquivos/pdf/bps.pdf. Acesso em: 24 set. 2018.

LEIVAS, Paulo Gilberto Cogo. Teoria dos direitos fundamentais sociais. Porto Alegre: Livraria do Advogado, 2006.

LIEBGOTT, Roberto Antonio. Os direitos humanos dos povos indígenas: os povos Guarani, Kaingang e Charrua e a contínua luta pela garantia de seus direitos. In: RIO GRANDE DO SUL. Assembleia Legislativa. Relatório azul 2011. p. 281-308. Disponível em: http:/www.al.rs.gov. br/FileRepository/repdcp_m505/CCDH/RelAzul/reazul_2011.pdf. Acesso em: 23 nov. 2021.

MAIS de um bilhão de pessoas no passam fome no mundo, diz ONU. BBC News Brasil, Brasília, 2009. Disponível em: http://www.bbc.com/portuguese/lg/noticias/2009/10/091014_ fomerelatorioonufn.shtml. Acesso em: 24 set. 2018.

MALUF, Renato S. Segurança alimentar e fome no Brasil -10 anos da cúpula mundial de alimentação. Rio de Janeiro: Ceresan, 2006. Disponível em: http://www.bvsde.ops-oms.org/ texcom/nutricion/relatoriotecnico2.pdf. Acesso em: 24 set. 2018.

ORGANIZAÇÃO DAS NAÇÕES UNIDAS. Após uma década de queda, fome volta a crescer no mundo. 18 set. 2017. Disponível em: https://nacoesunidas.org/onu-apos-uma-decadade-queda-fome-volta-a-crescer-no-mundo/. Acesso em: 24 set. 2018.

ORGANIZAÇÃO DAS NAÇÕES UNIDAS. Comitê de Direitos Econômicos, Sociais e Culturais do Alto Comissariado de Direitos Humanos (CESCR). Comentário geral número $12 \mathrm{O}$ direito humano à alimentação (art.11). [Genebra]: ONU, 1999. Disponível em: http://www.sesc.com.br/mesabrasil/doc/Direito\%20humano\%20\%C3\%A0\%20 Alimenta\%C3\%A7\%C3\%A3o-Seguran\%C3\%A7a-alimentar.pdf. Acesso em: 24 set. 2018.

ORGANIZAÇÃO DAS NAÇÕES UNIDAS. Cúpula Mundial de Alimentação. Declaração de Roma sobre a segurança alimentar mundial e plano de ação da cúpula mundial da alimentação. [Genebra]: ONU, 1996. Disponível em: http://www. direitoshumanos.usp.br/index.php/FAO-Food-and-Agriculture-Organization-of-the-United- 
Nations-Organiza\%C3\%A7\%C3\%A3o-das-Na\%C3\%A7\%C3\%B5es-Unidas-para-aAlimenta $\% \mathrm{C3} \% \mathrm{~A} 7 \% \mathrm{C} 3 \% \mathrm{~A} 3 \mathrm{o}-\mathrm{e}-\mathrm{a}$-Agricultura/cupula-mundial-de-alimentacao-declaracaode-roma-sobre-a-seguranca-alimentar-mundial-a-plano-de-acao-da-cupula-mundial-da-al.html. Acesso em: 24 set. 2018.

ORGANIZAÇÃO DAS NAÇÕES UNIDAS. Declaração Universal dos Direitos Humanos [Genebra]: ONU, 1948. Disponível em: http:/www.mp.go.gov.br/portalweb/hp/7/docs/ declaracao_universal_dos_direitos_do_homem.pdf. Acesso em: 26 dez. 2018.

ORGANIZAÇÃO DAS NAÇÕES UNIDAS. Declaração das Nações Unidas sobre Direitos dos Povos Indígenas. [Genebra]: ONU, 2007. Disponível em : https://pib.socioambiental. org/files/file/PIB_institucional/DECLARACAO_DAS_NACOES_UNIDAS_SOBRE_OS_ DIREITOS_DOS_POVOS_INDiGENAS.pdf. Acesso: em: 26 dez. 2018.

ORGANIZAÇÃO DAS NAÇÕES UNIDAS PARA A ALIMENTAÇÃO E A AGRICULTURA (FAO). América Latina e o Caribe - Panorama da segurança alimentar e nutricional: sistemas alimentares sustentáveis para acabar com a fome e a má nutrição 2016. Santiago: FAO; OPAS, 2017. Disponível em: http://www.fao.org/3/a-i6977o.pdf. Acesso em: 24 set. 2018.

\section{ORGANIZAÇÃO DAS NAÇÕES UNIDAS PARA A ALIMENTAÇÃO E A AGRICULTURA} (FAO). Mau tempo faz subir os preços dos alimentos em outubro. Roma, 5 dez. 2015. Disponível em: http://www.fao.org/news/story/pt/item/342513/icode/. Acesso em: 26 dez. 2018.

PEREIRA, Ana Lúcia. Famílias quilombolas: história, resistência e luta contra a vulnerabilidade social, insegurança alimentar e nutricional na comunidade Mumbuca - Estado do Tocantins. 2012. 3009 f. Tese (Doutorado em sociologia) - Universidade Estadual Paulista, Araraquara, 2012. Disponível em: http://base.repositorio.unesp.br/bitstream/handle/11449/106244/pereira al_dr_arafcl.pdf?sequence=1\&isAllowed=y. Acesso em: 24 set. 2018.

PINHEIRO, Elysângela Sousa; THOMAS, Shaji. Alimentação como direito social na Índia e no Brasil: breve análise comparativa. Disponível em: https://revistajuridica.presidencia.gov.br/ index.php/saj/article/view/120. Acesso em: 09 out. 2018.

PIOVESAN, FLÁVIA. Pobreza como violação de direitos humanos. In: NOLETO, Marlova Jovchelovitch; WERTHEIN, Jorge. (org.). Pobreza e desigualdade no Brasil: traçando caminhos para a inclusão social. Brasília: UNESCO, 2003

SANTILLI, Juliana. Socioambientalíssimo e novos direitos: proteção jurídica à diversidade biológica e cultural. São Paulo: Peirópolis, 2005. Disponível em: http://www.ethno-terroirs. cnrs.fr/gestion/applis/apetit/fichiers/UNIVERSIDADEDEBRASILIA-SANTILLI_JulianaSocioambientalismo-e-novos-direitos.pdf. Acesso em: 26 set. 2018.

SANTOS, João vitor. Genocídios dos povos indígenas. Revista Instituto Humanitas Unisinos, São Leopoldo, v. 15, n. 478, 2015. Disponível em: http://www.ihuonline.unisinos.br/media/pdf/ IHUOnlineEdicao478.pdf. Acesso em: 26 set. 2018.

SANTOS, Maureen; GLASS, Verena. Atlas do agronegócio 2018. Fatos e números sobre as 
corporações que controlam o que comemos. Rio de Janeiro: Fundação Heinrich Böll, 2018. Disponível em: https://br.boell.org/sites/default/files/atlas_agro_final_06-09.pdf. Acesso em: 23 nov. 2021.

SILVA, José Afonso da. Parecer sobre marco temporal e renitente esbulho. São Paulo, 2016. Disponível em: https://mobilizacaonacionalindigena.files.wordpress.com/2016/05/parecerjosc3a9-afonso-marco-temporal_.pdf. Acesso em 29 mar. 2018.

SILVA, José Graziano da. O combate à fome no Brasil. In: NOLETO, Marlova Jovchelovitch; WERTHEIN, Jorge. (org.). Pobreza e desigualdade no Brasil: traçando caminhos para a inclusão social. Brasília: UNESCO, 2003.

\section{SILVA, Sandro Pereira. A trajetória histórica da segurança alimentar e nutricional na} agenda política nacional: projetos, descontinuidades e consolidação. Rio de Janeiro: IPEA, 2014. Disponível em: http://repositorio.ipea.gov.br/bitstream/11058/3019/1/TD_1953.pdf. Acesso em: 23 nov. 2021.

SITUAÇÃO atual das terras indígenas. Terras indígenas no Brasil. Disponível em: https:// terrasindigenas.org.br/. Acesso em: 23 nov. 2021.

SOUZA, José Otávio Catafesto de. Os Mbyá-Guarani e os impasses das políticas indigenistas no sul do Brasil. In: REUNIÃO DE ANTROPOLOGIA DO MERCOSUL "DIVERSIDADE E PODER NA AMÉRICA LATINA”, 8., 2009, Buenos Aires. Anais [...]. Buenos Aires, 2009. Disponível em: https://pt.scribd.com/document/327925395/3textosouza-Catafesto-os-MbyaGuarani. Acesso em: 26 set. 2018.

TEMPASS, Mártin César. Comida e gênero entre os Mbyá-Guarani. Caderno Espaço Feminino, Uberlândia, v. 19, n. 1, p. 287-309, jan./jun. 2008. Disponível em: http://www.seer. ufu.br/index.php/neguem/article/view/2112/1733. Acesso em: 26 set. 2018.

TESTA, Adriana Queiroz. Caminhos de saberes Guarani Mbya: modos de criar, crescer e comunicar. 2014. 307 f. Tese (Doutorado em Antropologia) - Faculdade de Filosofia, Letras e Ciências Humanas da Universidade de São Paulo. São Paulo. 2014. Disponível em: http://www. teses.usp.br/teses/disponiveis/8/8134/tde-01062015-173729/pt-br.php. Acesso em: 26 set. 2018.

TUBINO, José. A contribuição da FAO para o combate à fome. In: NOLETO, Marlova Jovchelovitch. WERTHEIN, Jorge. (org.). Pobreza e desigualdade no Brasil: traçando caminhos para a inclusão social. Brasília: UNESCO, 2003.

VALENTE, Flávio Luiz Schieck. Direito humano à alimentação: desafios e conquistas. São Paulo: Cortez, 2002. Disponível em: https://books.google.com.br/books/about/Direito humano_\%C3\%A0_alimenta\%C3\%A7\%C3\%A3o.html?hl=pt-BR\&id=w4BFAAAAYAAJ. Acesso em: 24 set. 2018.

Como citar: STARCK, Gilberto; BRESOLIN, Keberson. A indispensabilidade da terra para a efetivação do direito humano ao alimento dos povos indígenas. Revista do Direito Público, 
Londrina, v. 16, n. 3, p. 123-143, dez. 2021. DOI: 10.5433/24157-108104-1.2021v16n3p.123. ISSN: 1980-511X

Recebido em: 12/11/2019

Aprovado em: 01/09/2020 